\title{
Verbal Communication Behaviors: How Male and Female University Students Interact in Gendered Talks
}

\author{
Kenneth G. Opina \\ Department of Communications, Linguistics, and Literature, University of San Carlos, Cebu City, Philippines
}

Email address:

ken.opina@gmail.com

To cite this article:

Kenneth G. Opina. Verbal Communication Behaviors: How Male and Female University Students Interact in Gendered Talks. International Journal of Language and Linguistics. Vol. 5, No. 5, 2017, pp. 135-142. doi: 10.11648/j.ij11.20170505.13

Received: July 4, 2017; Accepted: July 18, 2017; Published: August 16, 2017

\begin{abstract}
With the existence of language and gender studies emphasizing the male and female dichotomy in interactional strategies, this study aimed to investigate the verbal communication behaviors of language classroom mixed-gender and samegender group conversations involving the same interlocutors. The transcribed data obtained from the three fifteen-minute recorded group interactions indicated that questions and expressions of agreement were the typical behaviors employed by the interlocutors. The results showed that aside from the gender of the interlocutor and the gender composition of the group, the nature of talk and the group size influence the use of particular behaviors. The findings have implications on providing a locally-acquired data on classroom peer talks in the field of language and gender.
\end{abstract}

Keywords: Mixed-Gender, Same-Gender, All-Male, All-Female, Peer Talk, Interactional Strategies

\section{Introduction}

"Over the last twenty years, there has been an explosion of research in the field of language and gender" [7]. Researchers aimed at qualifying the differences of male and female discourse features. Sociolinguistic studies have "aimed to quantify the differences in women's and men's usage of certain linguistic forms" during conversations [6]. This practice has given several interpretations in understanding gender differences in various talk contexts. Gendered conversational style studies have brought attention to the idea that men and women talk differently and have contended that the interlocutor's gender dictates the way he/she behaves in an exchange.

Notably, the studies on this area make use of the term gender rather than sex despite the idea that interlocutors are grouped according to their sex. Gender appears to be a sideeffect of sexual reproduction on the human brain. Bleier "asserted that re-ported [sic] sex differences in brains predominantly reflect environmental factors - a matter of gender not sex" [38]. In addition, the linguistic behaviors of men and women are brought about by social factors. Deaux and LaFrance defined gender as a social construct which plays a vital role in social processes such as communication, which is a venue for gender to express its influence [27].
Most studies on language and gender stress that females are generally cooperative in nature whereas males are competitive [4]. However, an analysis of an all-male recorded conversation contradicts previous constructs in language and gender such as "Tannen's contention that men do not do 'women's talk' .... [3]" His findings based on the utilization of gossip illustrate that men engage in both competitive and cooperative talk thereby making all-male talk very much akin to an all-female talk. Furthermore, Hewitt [3] had similar findings as he was able to observe an occurrence of a collaborative talk in a game of same age secondary school boys in London.

Gender talk has been studied in various settings and context (i.e. play, classroom, and office). The classroom has been an interesting setting for researchers looking into gendered talk. Chavez [3] argued that "gender-linked research can be applied readily in an actual classroom setting" and that findings are valuable in the field of language and gender research. Remarkably, "classroom talk is an interesting area of study partly because many educationists argue that talk itself is an important vehicle for learning: .... [34]" Nevertheless, classroom talk studies often involve the teacher who controls the interaction.

Despite the numerous studies on language and gender, most of the earlier researches are focused on "English-speaking cultures and white, middle-class speakers" [7]. Thus, the 
community of practice (Cof P) formulated by Wenger highly encourages more research to broaden horizons by studying other conversational features in relation to gender in different cultures [7].

In the Philippines, studies focusing on language and gender have been conducted in the past few years. Even though these studies aimed to qualify the gender differences of Filipino males and females in mixed-gender settings, these researches looked into couple interactions, which include issues on inequality of status and power in the household [10] [23]. On the other hand, gender studies have also been conducted on male and female students, but focused on the use of the national language - Filipino. The findings of the researches suggest that there are indeed differences in males' and females' use of linguistic features [24] [25] [26].

As such, there is a need to determine the verbal communication behaviors of interlocutors in the language classroom collaborative conversations between mixed- and same-gender groups to provide more conclusive findings since previous studies conducted had different participants in each group. Having the interlocutors for the same-gender conversations (all-male and all-female groups) fused for the mixed-gender conversation will definitely show a more vivid picture of how an interlocutor communicates in group conversations. Such methodology will answer the question as to how gender affects verbal communication behaviors when conversing with others from the same and/or opposite genders.

Furthermore, classroom talk studies generally focus on conversations in the classroom setting between the students and the teacher rather than among students alone where the teacher affects the interaction [34]. To focus mainly on the interactions among student-participants and eliminate the idea that teachers aid in the dominance of a particular gender, the present set-up prevents the occurrence of a gender-biased conversation in the classroom.

\section{Theoretical Framework}

The conversational principles introduced by researchers of language and gender were based on the findings of studies which explored various features of interaction. Turner, Dindia, and Pearson [36] itemized 11 communication behaviors which differentiate male verbal behaviors from those of females. Their study focused on the following behaviors: talk time, vocalized pauses, verbal fillers, interruptions, overlaps, questions, tag-end questions, intensifiers, justifiers, hedges, and expressions of agreement as they are recurrently used and evaluated in studies concerning language and gender during same-gender and mixed-gender talks.

Turner, Dindia, and Pearson [36] determined the talk time of each participant in a conversation by counting the words in the utterances of each interlocutor. Evidently, the term talk time is used to refer to the complete words uttered instead of the minutes consumed by each speaker in the course of the interaction. Chavez [4] however, defined talk time in terms of the amount of time a speaker is given to share ideas as well as the license to participate in the exchange. The present study determined the talk time of every interlocutor by counting the complete words uttered.

They also identified vocalized pauses and verbal fillers as verbal behaviors utilized to fill a silence [36]. The former are non-words such as ah, er, um, etc., which are not part of the vocabulary and do not have meanings while the latter are meaningless words and/or phrases such as you know. Furthermore, Eakins and Eakins [11] added that verbal fillers are used to connect the utterances of the interlocutors in a conversation and are employed to indicate a speaker's hesitancy during interaction.

In conversations, the concept of floor, known as the "conversational space available to speakers"[4], is open to every interlocutor as it becomes a venue for exchanging utterances which includes both the amount of time a speaker is given to share ideas as well as the license to participate in the exchange. With such turn-taking rules, the two kinds of turn-taking behavior are distinguished - interruption and overlap.

Interruption is a "simultaneous speech in which a listener speaks at a point that was not a possible completion point for the speaker's utterance" [36]. In other words, it is characterized by the replacement of a speaker holding the floor causing a sudden end in the previous speaker's turn. Coates [7] further added that interruption is a technique in dominating the floor by denying speakers or trying to deny them of their right to interact. As such, it becomes a violation of the prescribed turn-taking rule where another speaker may only hold the floor if and when the present speaker has reached the end of the statement.

On the other hand, overlap is a "simultaneous speech in which a listener speaks at or very close to a possible transition place or ending point in the speaker's talk" [36]. Such simultaneous holding of the floor of two speakers is due to over-anticipation of a speaker's end of utterance [11]. Thus, it does not aim for dominance but rather promotes mutual reinforcement and shows active listenership [7].

Questions, or interrogatives, are also utilized in conversations which is one strategy used to begin or continue a talk [7]. Here, a speaker who poses a question is given the authority to elicit responses from the listener/s and thus ensures that the speaker is able to control what the addressee is supposed to say. The use of questions creates an assurance of continuing the conversation as these questions require answers, thereby making them stronger than a simple declarative statement.

A common type of question used is tag-end, which is declarative or imperative in nature but with a dependent interrogative clause attached in sentence-final position. This is an utterance that falls between an interrogative and a declarative statement, and softens the impact of a speaker's claim [7] or a means of refraining from uttering a strong statement [11], thus becoming a tool for politeness. Three contexts where tag-end questions are used were enumerated: (1) when the speaker only has partial information about the topic; (2) when asking something that does not need a 
confirmation from the hearers; and (3) when requesting for an approval. In Philippine English however, tag questions are actually few [1].

Individual words may also be strengthened by the preceding word in a statement. Expressions such as so, awfully, and quite increase the intensity of the succeeding word and are thus termed as intensifiers. In some instances, an interlocutor provides a reason for a given claim or suggestion with the help of justifiers. However, these were not utilized in the studied conversations.

In contrast, qualifiers such as pretty, kind of, and almost in the phrases 'pretty good', 'kind of fun', and 'almost correct' [36] and expressions such as I think, I'm sure, sort of, and perhaps mitigate the impact of the succeeding word or phrase. Otherwise known as hedge, this behavior is employed by speakers to soften an idea, a comment, or a suggestion raised in order to sound polite. These hedging devices were also referred to as epistemic modals [6], and show certainty or uncertainty of a speaker on a claim, thereby, making the statements tentative. There are also cases where an interlocutor outrightly agree such as you're right or I agree known as expression of agreement which aims to accept an idea advanced by another member of the group.

Aside from the behaviors previously mentioned, more recent studies have included minimal responses and discourse markers frequently used by males and females in conversations. Also known as back-channels, such as um and ah, these are employed to either emphasize dominance or affirm active listenership [7]. This strategy is similar to verbal fillers and vocalized pauses. One of the noticeable features of naturally-occurring conversations, discourse markers or DMs aid in the flow of interaction. DMs demonstrate a connection among discourse segments in an utterance [13]. Moreover, despite not having grammatical meaning, $D M s$ are employed to start a turn or illustrate their attitude toward the preceding and/or succeeding segments [31].

Studies on language and gender have focused on the interactional strategies utilized by interlocutors during conversations. Researchers have tried to associate these behaviors with regard to a speaker's gender as well as group composition. These behaviors have been the bases for the various frameworks used by linguists in conducting critical analyses of the corpus and in explaining the similarities and differences observed.

One of these frameworks is the deficit approach, which examines language based on specified standard and nonstandard (deficient) categories of language users. This framework sees male language as normative, where women, as the inferior users of language, speak a powerless language; hence, they are referred to as the muted group [28]. Similarly, the dominance approach views women in general as oppressed linguistically since they are dominated by men.

On the contrary, the difference framework by Maltz and Borker popularized by Tannen [28], believes that men and women, in general, speak different genderlects caused by early socialization with same-gender peers. Another framework which focuses on the construction of gender with regard to cultural variables (e.g., race, ethnicity, geography, class, and economics) is the discursive approach. The concept of gender therefore zooms in on the behavior adopted by interlocutors "in order to facilitate meaning and about how we perform our various transactions" [21].

The first three approaches took into consideration the gender variances in language based on the male-female dichotomy whereas the most recent one is within the bounds of a cultural framework. These approaches paved the way for conversational principles, termed as cooperation or collaboration and competition which center on the predominant view on the nature of male and female speeches.

"Co-operativeness refers to the particular type of conversation where speakers work together to produce shared meanings" while competitiveness, on the other hand, "is used to describe the adversarial style of conversation where speakers vie for turns and here participants are more likely to contradict each other than to build on each other's contribution" [6].

According to Chavez [4], "most researchers agree, with some concessions, that females adhere to a more cooperative speech style compared to males, who favor a more competitive-aggressive one." Several researchers are in agreement that females intend to interact and strengthen bonds by taking supportive roles whereas males dominate others and assert status by exhibiting power [4] [15]. Furthermore, "gender differences appear because of the fact that boys and girls are differently socialized" [9]. The differences in interactional style between genders affect the features of speech and interaction during same- and mixedgender conversations.

\section{Methodology}

The present study investigated conversations of small groups involving six student-participants, three males and three females, chosen through purposive non-probability sampling. These language class students were given the opportunity to group with their friends for the planning of a final class magazine project. Similar initial tasks were given to the participants during their separate same-gender conversations (i.e., all-male and all-female). These two groups were then fused afterwards for the mixed-gender interaction's additional task. The same participants were involved in both the mixed-gender and the same-gender (allmale and all-female) conversations to provide more conclusive results.

All three fifteen-minute group conversations (i.e., mixedgender, all-male, and all-female) were audio-tape recorded. With the addition of an instruction sheet and a layout sheet for every group to direct the participants' attention to the task instead of the recorder, only the first two minutes of the conversations were excluded from the analysis to address methodological issues.

Each group conversation was then transcribed for analysis. 
For coding purposes, each interlocutor was assigned a specific number (e.g., M 1, M 2, F 3, etc.) to easily determine the behaviors employed by each participant in both the samegender and mixed-gender interactions. Moreover, the utterances in every speaking turn of the participants were numbered chronologically beginning with the all-male conversation, followed by the all-female talk, and the mixedgender conversation.

In cases where the interlocutors code-switched and/or code-mixed between English and their native tongue Cebuano-Bisaya (CB), the utterances in $\mathrm{CB}$ were glossed.

The verbal communication behaviors espoused were identified from the utterances of the interlocutors and coded in terms of frequency, with the exception of talk time, which was ascertained by determining the number of complete words and non-words (i.e., verbal fillers) uttered by every participant were then tabulated and graphed for analyses and interpretations.

\section{Results and Discussion}

The results yielded both a confirmation and a contradiction to existing bodies of literature and empirical studies in the field of language and gender, particularly in classroom interactions.

\subsection{Talk Time in Gendered Groups}

Table 1. Talk Time (Number of Words).

\begin{tabular}{lllll}
\hline Student- & \multicolumn{2}{l}{ Mixed-Gender } & Same-Gender \\
\cline { 2 - 5 } Participant & Frequency & Rank & Frequency & Rank \\
\hline M 1 & 445 & 2 & 252 & 4.5 \\
M 2 & 303 & 3 & 363 & 2 \\
M 3 & 136 & 5 & 161 & 6 \\
F 1 & 463 & 1 & 397 & 1 \\
F 2 & 148 & 4 & 274 & 3 \\
F 3 & 75 & 6 & 252 & 4.5 \\
TOTAL & 1570 & & 1699 & \\
\hline
\end{tabular}

The data illustrate that most of the participants have longer talk time during same-gender conversations compared with that of mixed-gender interaction. Noticeably also, a female student-participant (F 1) consistently had the most number of words (463) uttered during the talk in either group.

The longer talk time of the male participants in the mixedgender group compared to the females showed the active involvement of the male participants in the conversations. This concurs with Holmes' [15] reanalysis of mixed-gender classroom discussion groups which established that males consume longer talk time than females and that verbosity cannot be generalized as women's interactional feature [22].

Interestingly, only the male (M 1) participant who dominated the talk in the mixed-gender group had lesser talk time in the same-gender or all-male group (252) whereas the two females (F 2 and F 3) increased their talk time in the same-gender or all-female group from a mere 148 and 75 to 274 and 252 words respectively. This productiveness in contribution definitely reflects their more comfortable state in the same-gender group.

Their role in the group conversation was a factor in the counting of talk time. M 3 who was assigned to note the suggestion on the draft layout had the lowest 136 words in the mixed-gender group; M 1 who drafted the layout for the same-gender group was reduced from 445 to 252 words.

This finding signifies that the group composition in terms of gender is not the only factor that affects the verbal behavior of a participant but also the group size. The number of interlocutors in a group and the roles or tasks performed by the speakers likewise influences their talk time. According to Levine and Moreland [37], there is lesser participation and cooperation in larger groups. As Lou, et al. [37] stated, the ideal size for collaborative classroom group activities is three to four members, but this was not the case during the mixed-gender session in the present study.

This supports the conclusion of Freed and Greenwood [14] that it is the nature of the conversational activity "not the sex or gender of the speaker, motivates and thus explains the language forms that occur in the speech of the" participants.

\subsection{Verbal Communication Behaviors in Gendered Groups}

\begin{tabular}{|lll|}
\hline QVocalized Pause & QVerbal Filler & QInterruption \\
QOverlap & Question & QQualifier \\
QAgreement & QMinimal Response & QDiscourse Marker \\
\hline
\end{tabular}

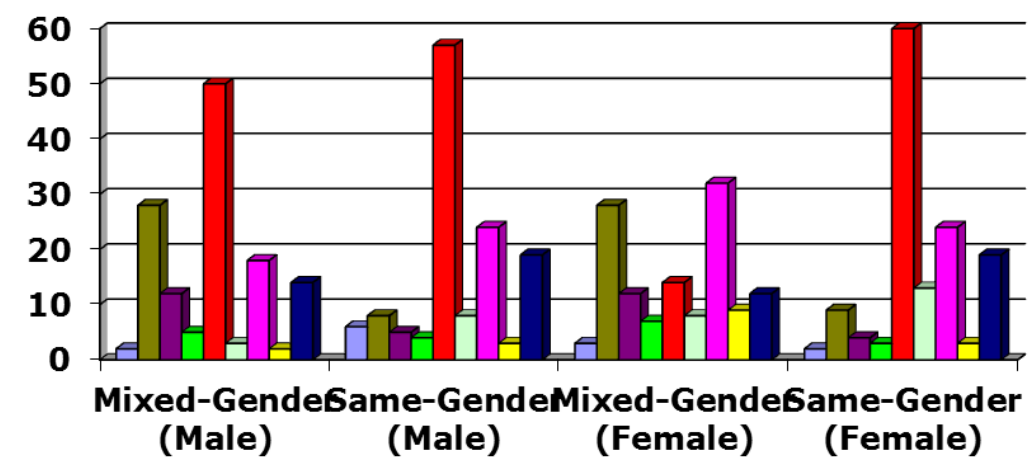

Figure 1. Verbal Communication Behaviors in Mixed-and Same-Gender Groups. 
Figure 1 exemplifies that the frequency of occurrence of verbal communication behaviors employed by males and females in small group conversations are almost the same in mixed-gender session (133 and 125) and in same-gender sessions (134 and 137).

Evidently, both genders had an increase in behaviors employed during same-gender groups. The frequency count indicates that male and female interlocutors typically used the same behaviors in both mixed-gender and same-gender sessions, such as questions $(50,57$ and 14, 60), expressions of agreement (17, 24 and 32, 24), discourse markers $(14,19$ and 12, 19), and verbal fillers $(28,8$ and 28,9$)$.

The collaborative nature of the activity influenced the frequent use of questions to seek information or suggestions in order to initiate the start (3 M 1) or ensure the progress (144 F 1) of the conversation by seeking the opinion of the other interlocutors. Questions were also used to clarify or confirm points raised (231 M 1 and 383 F 2).

Furthermore, tag-end questions (142 M 2, $170 \mathrm{M} \mathrm{2,} \mathrm{and}$ 818 F 2) were utilized for clarification. The employment of questions throughout the conversation was meant to indicate support, active involvement, and collaboration of ideas among members without being imposing when presenting their suggestions.

$3 \mathrm{M}$ 1: No, before the layout, what are we putting in the print ad?

144 F 1: You want it like that? Or like

$231 \mathrm{M} \mathrm{1:}$ The what?

142 M 2: There's a guy and then balloon ( ) diri na noh? Nya $=$

'There's a guy and then balloon ( ) here right? Then' =

170 M 2: Print ads are supposed to be kanang murag black and white, right?

Print ads are supposed to be something like black and white right?'

818 F 2: Pero there's a name naman in the kuan, diba?

But there's already a name in the article, right?'

Questions are tools in opening a topic and assuring the continuation of interaction among the participants [7]. This strategy is useful to ensure that the discussion is started and continued since questions elicit responses. Throughout the discussion, questions also neutralized the impact of suggestions advanced for the approval of the group. This is what the student-participants in the present study did in order to accomplish the assigned task. Although asking questions is generally associated with females, Michael, Chone, Muthusamy, and Veeravagu [22] stressed the idea that female interlocutors employing more questions than males is not necessarily the case.

Moreover, the tag-end questions, all used for clarification, strengthen the idea that one function of such type is to seek approval from the members of the group [11]. However, the minimal occurrence of tag-end questions in all groups is due to the fact that there are only a few of this type of question in the local language [1].

In relation to questions, expressions of agreement were commonly used by both genders in the conversations as answers to the suggestions presented to the group. The expressions yeah, okay and the CebuanoBisaya word oo ('yes') and its shortened version o, as well as repetition of words previously uttered were used by the participants in either accepting a proposition or placing additional input.

41 M 2: Quality education

42 M 3: O, quality education $(0.10)$

'Yes, quality education' $(0.10)$

These expressions indicated their active listenership, involvement and support to the interaction [36]. Noticeably however, during the mixed-gender session, most questions came from the male participants as these were used to elucidate response for acceptance or rejection of their suggestions whereas most of the expressions of agreement were responses of the females. The results further strengthen findings that in mixed-gender conversations, women are prone to listening and attentiveness, as well as agreement [10]. The high occurrence of the two behaviors was due to the nature of the talk which is collaborative. In order for the participants to come up with a decision regarding the plans for their group output, suggestions had to be accepted, rejected, or modified.

Although the participants were aware that the activities were recorded, they did not have any idea as to what the task was until they were handed the instruction sheet. Thus, the activity was an impromptu task for the interlocutors. Unrehearsed and impromptu activities such as the task of the student-participants in the present study increased the presence of discourse markers [19] and verbal fillers [33].

The use of discourse markers in the student-participants' utterances such as the Cebuano-Bisaya non-words ay and aw as well as the English markers ah, oh, and so elucidated the purpose of a particular statement that follows [31]. Lines $356 \mathrm{~F} 1,379 \mathrm{M} \mathrm{3}$, and $411 \mathrm{M} 2$ exemplify that the use of ay in initial position means that a mistake is committed and needs to be corrected or for clarification, whereas aw in line 55 M 2 indicates that a realization about a previous proposition presented has been made by the speaker.

356 F 1: No don't put it there. Ay yeah, you could put it there.

379 M 3: Ay ay nalang uy. Wa sa, wa sa.

'Ay nevermind. Let's disregard it for now instead.'

411 M 2: College? Ay unsa? CAFA.

'College? Ay what was it? CAFA.

$54 \mathrm{M} 3$ : Home to the best.

55 M 2: Home, aw o ((laughs))

The inclusion of verbal fillers in the ideas they presented to the group were as well evident in the utterances. These meaningless words fill in the gap or the silence [36]. English filler such as like (148 F 1 and 236 M 2) as well as Cebuano- 
Bisaya fillers kanang, and kuan (236 M 2 and 331 M 2) surfaced as shown in the examples below.

148 F 1: = Like, no. It's like, sa center it's only like one. $=$ $=$ 'Like, no. It's like, in the center it's only like one. $=$

$236 \mathrm{M} \mathrm{2}$ : = so meaning so kanang, every balloon is saying like

331 M 2: Naa baya na silay promos (0.2.) kanang kuan

'They actually have promos' $(0.2)$ kanang kuan

In addition, the two types of simultaneous speech, interruptions and overlaps, were evident in the conversation since the activity required the participation of all the members. Since almost everyone had ideas and suggestions they wanted to present to the body, there were instances that interlocutors such as in lines $67 \mathrm{M} \mathrm{1,69} \mathrm{M} \mathrm{1,} \mathrm{70} \mathrm{M} \mathrm{2,} \mathrm{and}$ 742 F 1 interrupted another speaker holding the floor despite being far from the turn boundary while others tended to overlap by speaking when another person was about to end his/her utterance as in lines $339 \mathrm{M} 1$ and $743 \mathrm{~F} 3$.

66 F 1: = In Cebu (0.3) Let's, I think it needs to be a fact, kay kung ( )

$67 \mathrm{M} \mathrm{1:}$ What is a print ad man gyud? $(0.1)$

'=In Cebu (0.3) Let's, I think it needs to be a fact because if ( )'

'= What really is a print ad?' $(0.1)$

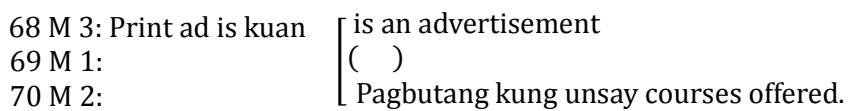

'Include the courses offered.'

338 F 3: Best Architectural [School

339 M 1: $\quad$ I: $: \mathrm{n}$ the Philippines

741 F 3: You can put $\left[\begin{array}{l}\text { here and just continue } \\ \text { Sa center na lang. Sa center na lang }\end{array}\right.$
742 F 1:

742 F 1: $\quad\left[\begin{array}{l}\text { Sa center na lang. Sa center na lang } \\ \text { sa, para sa, sa article. Ah, kanang murag = }\end{array}\right.$

'Just in the center since it's for the article. Ah, kanang somewhat like $="$

743 F 3: $=0$, o, i-center $(0.2)$ then continue the article here. Then start another article here. $=$

' $=$ Yes, in the center $(0.2)$ then continue the article here. Then start another article here. $=$ '

The male and female participants' employment of interruptions and overlaps during the interaction was evidently to move the conversation forward by adding or seeking for information and accepting ideas previously presented. These were not attempts to simply grab the conversational floor as commonly perceived and asserted by existing theories on language and gender, but rather to reinforce the solidarity of the group and the accomplishment of the task within the prescribed time. In addition, the presence of these two turntaking behaviors indicates that everyone in the group has the license to participate in the discussion.

In accordance with the findings of Turner, Dindia, and Pearson [36], interruptions were minimally utilized by males although this is supposedly a verbal communication behavior associated with men to ensure conversational dominance. Also, females tend to interrupt more than males do during same-gender conversations [20]. Even though the use of interruptions in the conversation contradicts the claim of Coates [7] that it is a means of hogging the conversational floor, the use of overlaps concurs with Eakins and Eakins' [11] assertion that these are due to over-anticipation of the turn boundary and eagerness to reinforce the ideas discussed.

Females clearly, "adhere to a more cooperative speech style" [4] as asserted by previous researchers [7] [15] on language and gender. Males, on the other hand, are also capable of promoting solidarity with one another and not just adhere to an adversarial style of interaction as depicted by earlier studies. This is in consonance with the assertions of Cameron [3] and Mojica [24] [25].

Aside from gender, other factors also played a vital role in the employment of behaviors. These are the size of the group and the nature of talk.

The smaller number of participants (three interlocutors) during the same-gender talks forced the group members to participate more actively causing the increased use of verbal communication behaviors. Student to student collaboration is greater in same-gender than mixed-gender classroom interactions [37]. Having more participants in a group conversation clearly signifies that the conversational floor may be held by several individuals. This will surely cause other interlocutors to assert their right to take charge of the floor while others may simply opt to become passive to avoid conflicts in obtaining the conversational space. Furthermore, a group with three to four members is the ideal size to ensure involvement and collaboration in classroom activities [37]. This idea is evidently confirmed by the results of the present study as observed in the total number of recorded behaviors employed by the interlocutors.

The employment of these conversational strategies indicates that the interlocutors aim to complete the task within the prescribed period of time since collaboration can be made possible with the use of these behaviors. Consequently, it is the nature of interaction that dictates the utilization of particular verbal communication behaviors during small group discussions among interlocutors. The collaborative nature of a planning or brainstorming activity ensures that members of a group participate and interact in order to arrive at a sound consensus of decisions to be made. In the present task, the cooperation among members of the group was necessary to achieve the group's goals or objectives within the prescribed time.

\section{Conclusions}

In order to gain better understanding on the intricacies of male and female verbal communication behaviors in mixedgender and same-gender conversations, the present study examined these strategies by having the same interlocutors in different group sessions.

The results indicated that gender influences the employment of specific interactional strategies during gendered talk. The verbal communication behaviors during all-male and all-female conversations were similar in both 
groups. The same findings showed in the behaviors employed by both males and females in the mixed-gender group. However, specific behaviors were exhibited more by a particular gender which conform to the findings of previous research studies on language and gender. Males utilize more vocalized pauses, interruptions, and overlaps than females do whereas the latter's utterances manifest greater verbal fillers, questions, and qualifiers/hedges than that of the former. This consistency in the findings indicates that verbal communication behaviors during same-gender interaction is indeed influenced by the gender of the interlocutor and the gender of the other speakers in the group.

Aside from the gender of the interlocutor and the gender composition of the group, behaviors are also affected by the size of the group. Smaller groups require more participation from members while bigger groups may shun other members from interacting. The size then promotes participation and interaction among the interlocutors thereby affecting the employment of the behaviors.

The verbal communication behaviors are also dependent on the nature of the conversation in gendered talk. The interactional strategies exhibited in all three talk sessions were evidently a product of the collaborative nature of the interaction as dictated by the task provided. This can be proven through the similarities of verbal communication behaviors employed in both the mixed-gender and the samegender conversations. The change in the frequency of occurrence of these behaviors was evident yet minimal. Thus, the objective of the interlocutors in relation to the task given affected the utilization of specific behaviors throughout the course of the conversations. The behaviors used were those that would advance the discussions and ensure unanimously accepted decisions.

Thus, aside from gender, group size as well as the nature or purpose of talk play an important role in the employment of interactional strategies. Verbal communication behaviors of males and females in small group conversations are actually shaped by the interplay of these various factors.

\section{References}

[1] Borlongan, A. (2008). Tag-questions in Philippine English. Philippine journal of linguistics, 39, 1, p. 109-133.

[2] Bunyi, J. (1986). Language, sex, and communication Implications for research in the Philippines. Philippine journal of linguistics, 17 , p. 65-69.

[3] Cameron, D. (1997). Performing gender identity: Young men's talk and the construction of heterosexual masculinity. in Johnson, S. \& Meinhof, U. (Eds.) Language and Masculinity. Oxford: Blackwell.

[4] Chavez, M. (2001). Gender in the language classroom. USA: McGraw-Hill Higher Education.

[5] Chen, L., et al. (2006). A multimodal analysis of floor control in meetings. Retrieved January 27, 2012 from http://www.cs.umd.edu/ zqhuang/index_files/MLMI 06.pdf.
[6] Coates, J. (1987). Gossip revisited: Language in all-female groups. In Coates, J. (ed.). (2004). Language and gender: A reader. UK: Blackwell Publishing.

[7] Coates, J. (2004). Women, men and language. $3^{\text {rd }}$ ed. Malaysia: Pearson Education Limited.

[8] Coates, J. \& Pichler, P. (Eds.). (2011). Language and gender: $A$ reader. $2^{\text {nd }}$ ed. UK: Blackwell Publishing Ltd.

[9] Cowie, C. (2000). Gender language-interruption and overlapping: How to interpret the two categories of simultaneous speech. Retrieved May 20, 2011 from http://www.lingutronic.de/Studium/Anglistik/Gender\%20Lang uage/Gender\%20Language.pdf.

[10] Dita, S. (2011). Slow down, women at work: An analysis of marital conversation. Issues and trends in applied linguistics in the Philippines: A decade in retrospect. Manila: DLSU Academic Publications Office, p. 223-239.

[11] Eakins, B. \& Eakins, R. (1978). Sex differences in human communication. USA: Houghton Mifflin Company.

[12] Fishman, P. (1978). Interaction: The work women do. Social problems, 25, 4, 397-406.

[13] Fraser, B. (1999). What are discourse markers? Journal of pragmatics. Retrieved August 5, 2012 from the World Wide Web at

http://www.gloriacappelli.it/wpcontent/uploads/2009/05/dm.pdf.

[14] Freed, A. \& Greenwood, A. (1996). Women, men, and type of talk: What makes the difference?. Language in society, 25, 126.

[15] Holmes, J. (1995). Women, men and politeness. London: Longman Publishers Inc.

[16] Krasny, K. (2013). Gender and literacy: A handbook for educators and parents. USA: ABC-CLIO, LLC.

[17] LaFrance, M. (1992). Gender and interruptions: Individual infraction or violation of the social order. Psychology of women quarterly, 16: 497-512.

[18] Laskowski, K. (2010). Modeling norms of turn-taking in multiparty conversation. Retrieved May 21, 2011 from the World Wide Web at http://aclweb.org/anthology/P/P10/P10-1102.pdf.

[19] Liu, B. (2009). Chinese discourse markers in oral speech in mainland Mandarin speakers. Proceedings of the $21^{\text {st }}$ North American conference on Chinese linguistics, 2: 358-374.

[20] McCloskey, L. \& Coleman, L. (1992). Difference without dominance: Children's talk in mixed- and same-sex dyads. Sex Roles, 27: 241-257. Retrieved December 4, 2011 from http://link.springer.com/article/10.1007\%2FBF00289927\#page-1.

[21] Mellor, B. (2012). Deficit, dominance, difference and discursive: The changing approaches to language and gender. Diffusion, 4, Issue 2.

[22] Michael, A., Chone, L., Mthusamy, C., \& Veeravagu, J. (2010). Gendered-linked differences in speech styles: Analysing linguistic and gender in the Malaysian context. Cross-cultural communication, 6, 1: 18-28.

[23] Mojica, L. (2011). The role of apologies in preserving couples' relationships. Issues and trends in applied linguistics in the Philippines: A decade in retrospect. Manila: DLSU Academic Publications Office, p. 131-139. 
[24] Mojica, L. (2000 a). How do selected students describe male/female language in Filipino? Philippine journal of linguistics, 31, 1, p. 67-78.

[25] Mojica, L. (2000 b). Gender differences in students' constructed dialogues using Filipino. Philippine journal of linguistics, 31, 2, p. 85-92.

[26] Montenegro, C. (1982). An exploratory study of male and female language in Pilipino. Philippine journal of linguistics, 13,1, p. $75-95$.

[27] Palomares, N. (2008). Gender and intergroup communication. in Giles, H. (2012). The handbook of intergroup communication. UK: Routledge.

[28] Pavlenko, A. \& Piller, I. (2008). Language education and gender. in May, S. \& Hornberger, N. (Eds.). Encyclopedia of language and education. ( $2^{\text {nd }}$ ed.). Volume 1: Language policy and political issues in education: 57-69.

[29] Piller, I. \& Pavlenko, A. (2006). Bilingualism and gender. in Bhatia, T. \& Ritchie, W. (Eds.). The handbook of bilingualism. UK: Blackwell Publishing.

[30] Psathas, G. (1995). Conversation Analysis: The study of talkin-interaction. USA: Sage Publications Inc.

[31] Rowe, B. \& Levine, D. (2012). A concise introduction to linguistics. $3^{\text {rd }}$ ed. USA: Pearson Higher Education Inc.

[32] Stenström, A.-B. (2004). An introduction to spoken interaction. London: Longman.
[33] Stenström, A.-B. (2011). Pauses and hesitations. in Andersen, G. \& Aijmer, K. (Eds.) Pragmatics in society. Germany: Walter de Gruyter GmbH \& Co. 537-568.

[34] Swann, J. (1993). Talk control: An illustration from the classroom of problems in analyzing male dominance of conversation. in Coates, J. \& Pichler, P. (Eds.). (2011). Language and gender: A reader. $2^{\text {nd }}$ ed. UK: Blackwell Publishing Ltd.

[35] Tannen, D. (1996). Researching gender-related patterns in classroom discourse. TESOL Quarterly, 30, No. 2: 341-344.

[36] Turner, L., Dindia, K., \& Pearson, J. (1995). An investigation of female/male verbal behaviors in same-sex and mixed-sex conversations. Communication reports, 8 , No. 2: 86-96.

[37] Wilkinson, I. \& Fung, I. (2002). Small-group composition and peer effects. International journal of educational research, 37, p. 425-447. Retrieved November 5, 2013 from http://citeseerx.ist.psu.edu/viewdoc/download?doi=10.1.1.136 $.228 \&$ rep $=$ rep $1 \&$ type $=$ pdf.

[38] Wood, J. \& Dindia, K. (1998). What's the difference? a dialogue about differences and similarities between women and men. in Canary, D. \& Dindia, K. (Eds.). Sex Differences and Similarities in Communication: Critical Essays and Empirical Investigations of Sex and Gender in Interaction. Mahwah, NJ: Lawrence Erlbaum Associates. 